\title{
Coral Distribution on Artificial Structures in Bonaire, Leeward Antilles
}

\author{
Genady Filkovsky ${ }^{*}$ and W. Wyatt Hoback
}

University of Nebraska Kearney, Biology Department, 905 W 25 $5^{\text {th }}$ St., Kearney, NE 68849, USA

\begin{abstract}
Distribution patterns of live scleractinian coral colonies on vertical faces of concrete blocks were compared with distribution patterns of environmental parameters known to affect coral recruitment and growth. Coral coverage was not random across the blocks and among regions of their faces. Variations in colonization did not correspond to differences in substrate type, illuminance, and water motion intensity. Coral distribution significantly correlated with blocks location and faces orientation, and these correlations depended on prevailing current direction. These correlations and dependencies are consistent with the hypothesis that the coral coverage was detrimentally affected by a low quality of water flow from the local marine port.
\end{abstract}

Keywords: Colonization, environmental factors, reef conservation, reef management, reef restoration, scleractinia, sedimentation, water quality.

\section{INTRODUCTION}

Physical environmental factors play a crucial role in coral settlement, survival, growth, and development. Such factors as increase in water temperature and acidity, or increase in strength and frequency of storms affect coral reefs on global and regional scales [1]. Factors such as coastal currents, water turbidity, and sedimentation have more localized effects [2, 3]. Even small local variations in physical environmental parameters may cause significant differences in coral reef establishment and persistence $[4,5]$.

It is often difficult to determine the effect of a specific environmental factor on coral communities due to many uncontrolled or unknown factors and because the age and history of the coral is usually unknown [6]. These difficulties are minimized in experimental settings where corals develop on simple artificial structures such as tiles and racks, in selected environments [7]. These studies provide data on settlement and initial survival, usually not on the subsequent growth and development of corals [8]. Some long term data are available from studies of coral reef development on artificial structures with well known history such as submerged constructions and ship wrecks [9, 10]. However, these data are often difficult to interpret because of the complexity of the structures and a multitude of environmental factors.

A rare opportunity to investigate long term coral development on simple artificial structures is provided by the boat mooring blocks installed along the coast of Kralendijk, Bonaire, Leeward Antilles. These are concrete blocks with dimensions of $1 \mathrm{~m} \mathrm{x} 1 \mathrm{~m} \mathrm{x} 1 \mathrm{~m}$ that were deployed by Bonaire National Marine Park between 1994 and 1996. The

*Address correspondence to this author at the Biology Department, University of Nebraska Kearney, $905 \mathrm{~W} 25^{\text {th }}$ Street, Kearney, Nebraska, 68849-1140, USA; Tel: 717-798-8498; E-mail: lagoenhill20@yahoo.com mooring blocks were installed on a flat bottom between the shore and the natural fringing reef, with about $50 \mathrm{~m}$ between the moorings. Their vertical faces are now partially covered with coral colonies that developed since the installation.

These simple structures have the same physical and chemical composition, surface texture, color, and deployment configuration. This setup allows for comparison of limited number of physical environmental parameters that vary among sites. Variables associated with the block locations consist of different depths, distances from the shore and from the reef, and locations of the blocks along the shore. Variations between the block faces consist of different exposure to light and currents due to different orientations.

The purpose of this study was to investigate the longterm relationship between the physical environmental factors and patterns of the coral distribution. The percentage of live coral coverage on the block faces was the dependent variable. This measure is a good estimate of the total amount of live coral in this study because only massive and encrusting coral species (of mostly genus Diploria with some Porites and Agaricia and much less significant contribution of other genera) have developed on the mooring blocks, with branching and columnar species absent.

The results of this study may contribute to the understanding of small-scale environmental effects on coral reef development, and may be helpful in future restoration projects.

\section{MATERIALS AND METHODS}

\section{Study Site}

This study focused on boat moorings used for rental by private yachts because these moorings are the most permanent compared to other moorings that are used by 


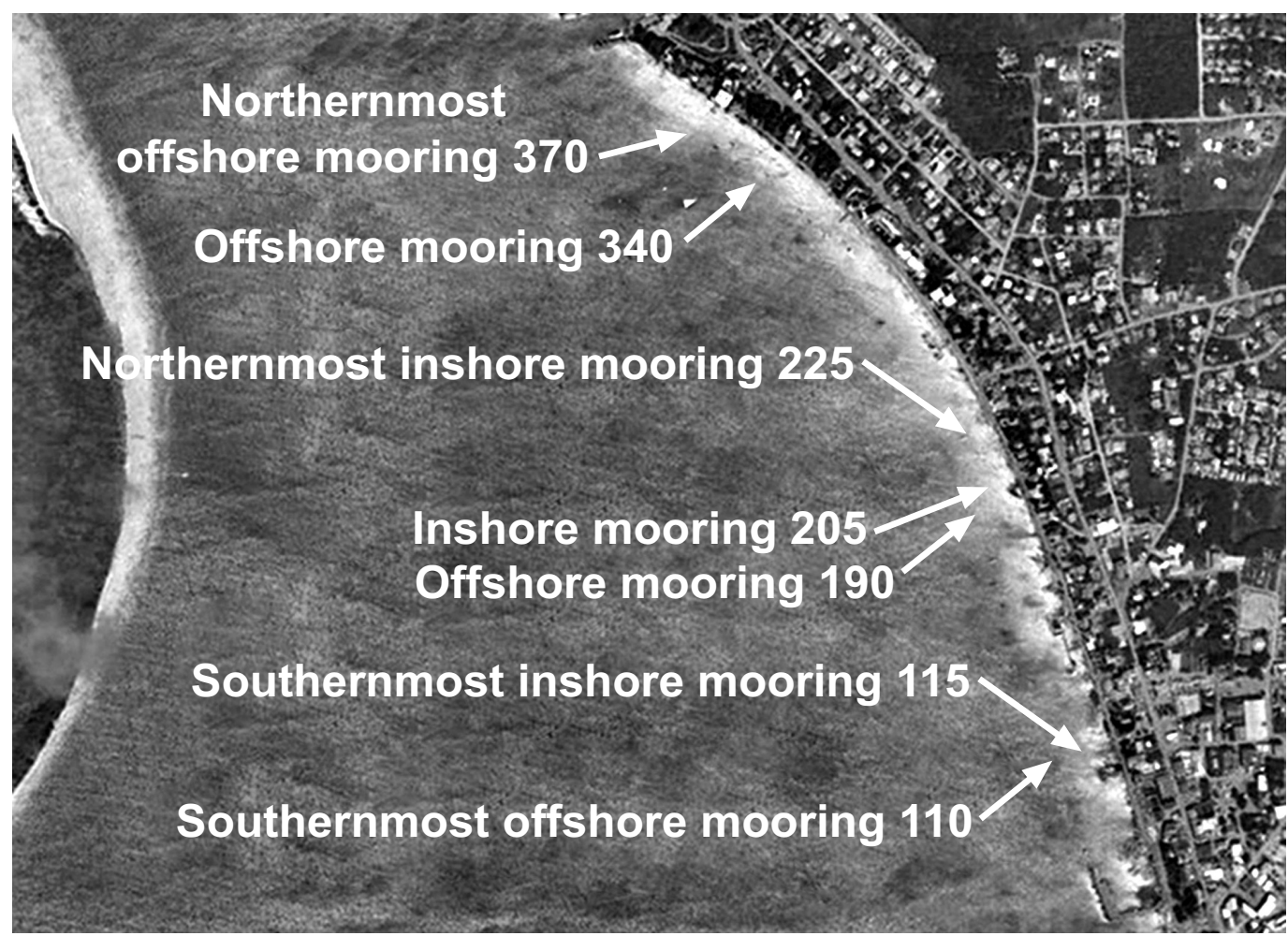

Fig. (1). Locations of boat moorings relative to shoreline of Kralendijk, Bonaire.

fishermen and sport divers. The moorings are located in front of the town of Kralendijk, on a reef flat between the shore and the reef drop-off. They are configured in lines parallel to shore and were studied as three distinct groups because of physical differences in their locations.

One group, in the inshore area, consisted of moorings located $35-40 \mathrm{~m}$ from shore, about half way between the shore and the reef drop-off, in $2.5-3.5 \mathrm{~m}$ of depth. The shore line and the line of the moorings are almost straight and run from southeast to northwest, in about $165^{\circ} / 345^{\circ}$ direction. The moorings are spread about evenly along the line, with about $1 \mathrm{~km}$ between the southernmost and the northernmost inshore moorings (Fig. 1).

The second group, in the southern offshore area, is positioned along a line parallel to the line of inshore moorings but farther from the shore and nearer to the reef drop-off. These moorings are located $70-80 \mathrm{~m}$ from shore in $4.5-5.5 \mathrm{~m}$ of depth (Fig. 1).

The third group, in the northern offshore area, consists of the moorings located farther northwest from the southern offshore moorings. They are positioned along about $1 \mathrm{~km}$ line that curves westward, in about $135^{\circ} / 315^{\circ}$ direction, parallel to the shoreline in that area. The moorings are located near the reef drop-off, like the moorings in the southern offshore area. The distance to shore in this area is $35-70 \mathrm{~m}$ and the bottom depth is $4.5-5.5 \mathrm{~m}$ (Fig. 1).

The inshore mooring area and the southern offshore mooring area are located between "Karel's Bar" and "Kas di Regatta" (Fig. 2), and the northern offshore mooring area continues farther northwest. The port of Kralendijk is less than $150 \mathrm{~m}$ south of the "Karel's Bar". Prevailing currents in the inshore and the southern offshore areas flow up the shoreline. The port activities, such as strong jets from powerful propellers of large ships, stir up the sediments and create a plume of muddy "marine snow" in the water column (personal observations). The prevailing currents slowly move this plume north along the reef drop-off, while the plume gradually settles, widens, and dissipates.

\section{Boat Mooring Installation History}

The moorings in these three groups were installed between 1994 and 1996. The offshore moorings were installed first, from south to north, and then the inshore moorings were added (Edwin Din Domacasse, Chief Ranger of the Bonaire National Marine Park who was responsible for the boat moorings' installation in the Park; pers. comm.)

\section{Coral Coverage}

The boat mooring blocks were photographed between Oct. 11, 2009, and Apr. 16, 2010. The photographs included each mooring's overall block configuration and every unobstructed vertical face. Each photograph was dated and marked with mooring ID, block location, and face orientation. Orientations of the vertical faces were identified by the compass bearing of the facing direction.

Blocks which did not move visibly from their location and position at the time of installation, were selected. Of these blocks, the vertical faces were selected which were exposed to their environment without being obstructed or shaded by adjacent blocks. Each of these faces were divided into four quadrants - upper left, upper right, lower left, and lower right - and areas covered by living scleractinian corals on each quadrant were measured. 


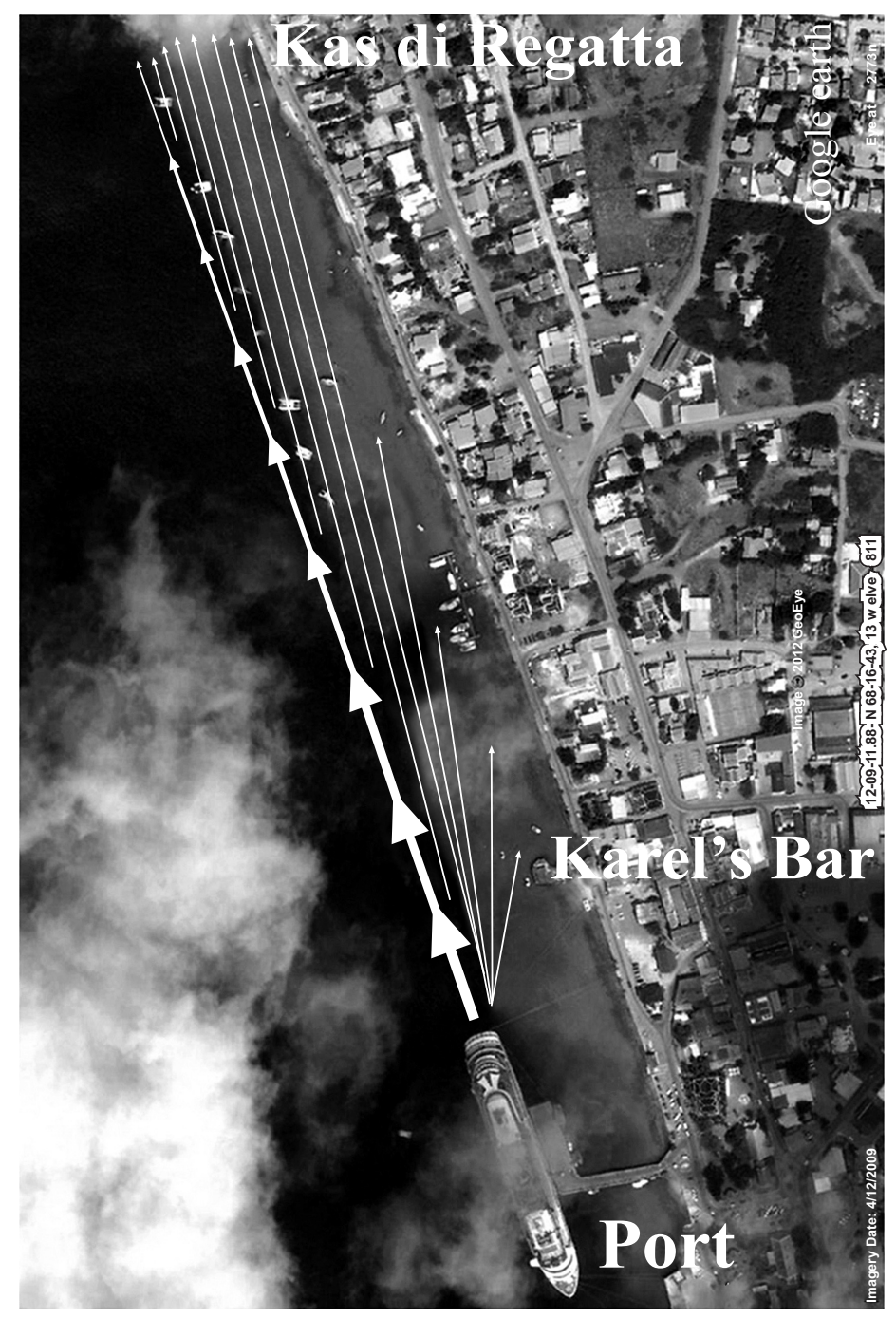

Fig. (2). The inshore and the southern offshore mooring areas and direction of sediment spreading.

\section{Light}

Light data were collected between Sep. 25, 2010, and Apr. 2, 2011, using HOBO Pendant ${ }^{\circledR}$ Temperature/Light Data Loggers 64K (Onset Computer Corporation, Pocasset, MA). The loggers continuously recorded light intensity every minute.

The light data were collected in three locations - around mooring 190 in the southern offshore area, mooring 340 in the northern offshore area, and mooring 205 in the inshore area (Fig. 1). At each location, five loggers were installed, facing northward, eastward, southward, westward, and upward. The loggers were installed on metal rods fastened to the bottom, near the block faces to measure the illuminance of each face with corresponding orientation.

The recordings were transferred weekly to a computer. After transferring the data, the loggers were reset, cleaned of sedimentation and growth, and randomly repositioned and reoriented.

\section{Currents}

Currents data were collected between Jul. 2, 2010, and Aug. 29, 2012, on random days and at random time between
08:00 and 17:00. The data were collected near the southern offshore mooring 190, the northern offshore mooring 340, and the inshore mooring 205 (Fig. 1). The currents were measured by a SCUBA diver hovering about $0.5 \mathrm{~m}$ above the bottom and drifting with the current. While passively drifting, the diver dropped two small weights one minute apart. The distance between the weights and their relative position provided measurement of the currents' velocity and direction.

\section{Integrated Water Motion}

To estimate integrated water motion caused by wave surge, tides, and currents, data on galvanic corrosion rates were collected [11, 12]. To compare between the three mooring areas, the data were collected at the southern offshore moorings 110 and 190, the northern offshore mooring 370, and the inshore moorings 115 and 205 (Fig. 1), in seven random 15-32 day periods between May 12, 2012, and Oct. 27, 2012. Zinc-copper galvanic pairs were attached to re-bars on top of the mooring blocks at the beginning of each period and removed at the end of each period. All zinc pieces used for each period were cut from the same zinc rod. After the removal, zinc pieces were cleaned for three 


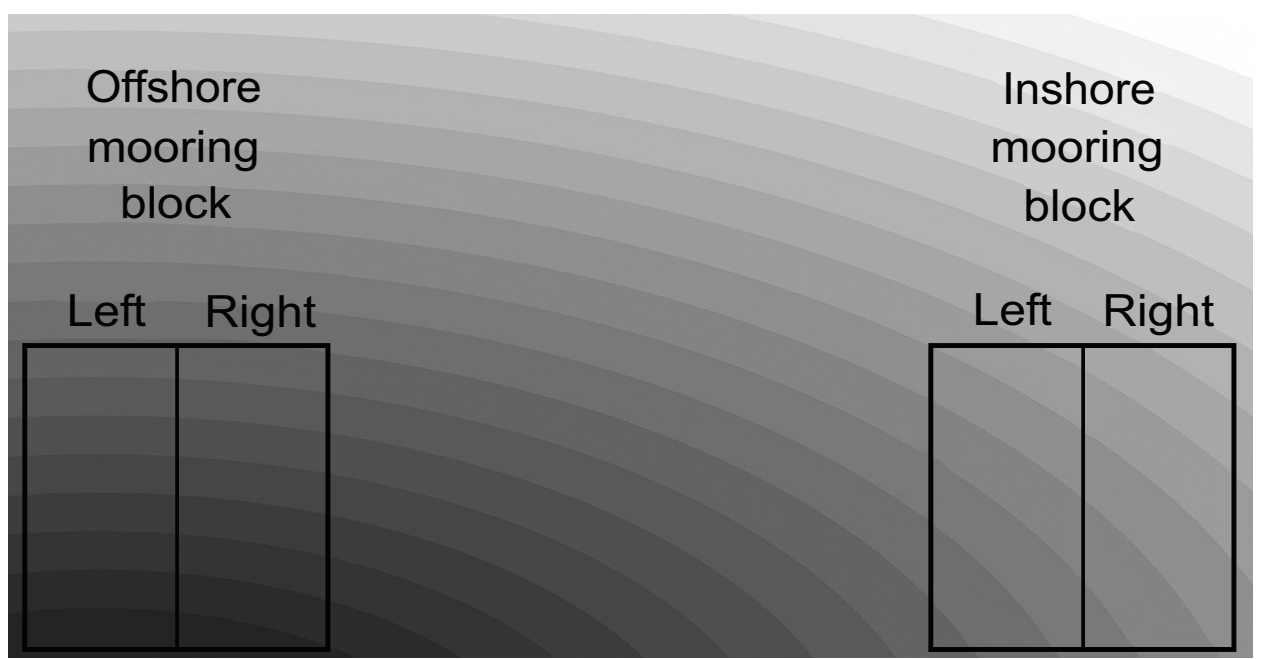

Fig. (3). Cross-section view of the suspended sediment plume drifting from the port in the direction with the current.

Table 1. Coral coverage on exposed mooring block faces by mooring areas.

\begin{tabular}{|c|c|c|c|c|}
\hline Mooring Area & Number of Faces & Mean Coverage, $\%$ & Minimum Coverage, \% & Maximum Coverage \\
\hline \hline Inshore & 61 & 25.4 & 1 & 49 \\
\hline Southern offshore & 32 & 12.3 & 1 & 27 \\
\hline Northern offshore & 34 & 20.7 & 44 \\
\hline
\end{tabular}

Table 2. Coral coverage by mooring area and orientation; mean coral coverage, \%, (number of faces).

\begin{tabular}{|c|c|c|c|c|}
\hline \multirow{2}{*}{ Mooring Area } & \multicolumn{4}{|c|}{ Face Orientation } \\
\cline { 2 - 5 } & North & East & South & West \\
\hline \hline Inshore & $24.8(14)$ & $25.8(17)$ & $9.3(12)$ & $24.2(18)$ \\
\hline Southern offshore & $13.0(9)$ & $13.7(10)$ & $21.0(9)$ & $11.8(5)$ \\
\hline Northern offshore & $25.1(8)$ & $21.0(7)$ & $16.6(10)$ \\
\hline
\end{tabular}

minutes in $10 \% \mathrm{HCl}$ solution. Weights of zinc pieces before and after each period were recorded.

\section{Statistical Analysis and Plume Model}

InStat software (GraphPad Software, La Jolla, CA) was used to calculate summary statistics and to run statistical tests. Vertical and horizontal distribution of suspended sediments in the "marine snow" plume was assumed qualitatively to be a normal Gaussian distribution (Fig. 3).

\section{RESULTS}

\section{Coral Coverage Patterns}

\section{Mooring Areas}

Coral coverage on exposed mooring block faces was compared between the three areas (Table 1). Kruskal-Wallis test (nonparametric ANOVA) showed significant differences among the median coverage $(\mathrm{KW}=22.7, \mathrm{P}<0.0001)$.
Dunn's multiple comparisons post-test showed that the median coverage was significantly higher for the inshore than the southern offshore $(\mathrm{P}<0.001)$ and for the northern offshore than the southern offshore $(\mathrm{P}<0.01)$ mooring areas. Coverage was not significantly different between the inshore and the northern offshore mooring areas.

\section{Face Orientation}

Coral coverage in each mooring area was compared among the faces oriented toward north, east, south, and west (Table 2). Kruskal-Wallis test failed to detect significant differences among orientations in every mooring area (inshore: $\mathrm{KW}=0.3943, \mathrm{P}=0.9414$; southern offshore: $\mathrm{KW}=1.834, \mathrm{P}=0.6076$; northern offshore: $\mathrm{KW}=2.220$, $\mathrm{P}=0.5280$ ).

Coral coverage differences among orientations were significant when compared by mooring areas. The coral coverage on northerly faces in the inshore mooring area was significantly higher than that of southerly faces in the southern offshore mooring area (Mann-Whitney test: $\mathrm{U}=19$, $\mathrm{P}=0.0126$ ). 


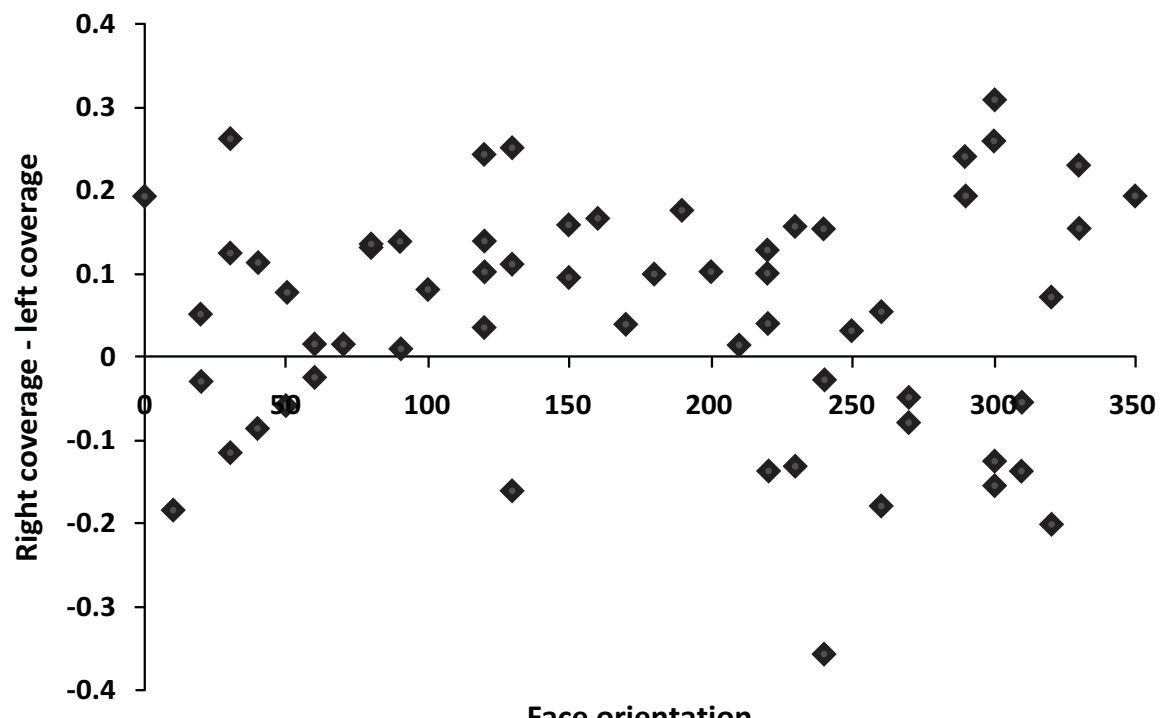

Fig. (4). Coral coverage difference between right and left halves of mooring block faces in the inshore mooring area, by face orientation.

Table 3. Daily light intensity between 06:00 and 18:00 by mooring area and orientation; mean daily light intensity, lux (number of days).

\begin{tabular}{|c|c|c|c|c|}
\hline \multirow{2}{*}{ Mooring Area } & \multicolumn{4}{|c|}{ Face Orientation } \\
\cline { 2 - 5 } & North & East & South & West \\
\hline \hline Inshore & $1,907(139)$ & $2,824(137)$ & $2,876(138)$ & $2,873(143)$ \\
\hline Southern offshore & $1,387(105)$ & $2,049(106)$ & $2,195(119)$ & $1,390(90)$ \\
\hline Northern offshore & $1,639(76)$ & $2,469(75)$ & $1,691(87)$ & $1,402(83)$ \\
\hline
\end{tabular}

\section{Right and Left Halves}

Coral coverage in each mooring area was compared between the right and the left halves of the faces. No significant differences were detected in the southern offshore area (Wilcoxon matched-pairs signed-ranks test: $\mathrm{N}=32$, $\mathrm{W}=-12, \mathrm{P}=0.9181$ ) or in the northern offshore area (Wilcoxon matched-pairs signed-ranks test: $\mathrm{N}=34, \mathrm{~W}=93$, $\mathrm{P}=0.4316$ ). But the coral coverage on the right halves of block faces in the inshore area was significantly higher than that on their left halves (Wilcoxon matched-pairs signedranks test: $\mathrm{N}=61, \mathrm{~W}=-769, \mathrm{P}=0.0058$ ).

Differences between the coverage on right and left halves of the mooring block faces in the inshore area depended on the face orientation (Fig. 4). Coral coverage on the right halves of the faces oriented down the shoreline $\left(80^{\circ}-250^{\circ}\right)$ was significantly higher than that on their left halves (Wilcoxon matched-pairs signed-ranks test: $\mathrm{N}=30, \mathrm{~W}=-276$, $\mathrm{P}=0.0047$ ). However, there was no significant difference between right and left half coverage on the faces oriented up the shoreline $\left(260^{\circ}-70^{\circ}\right)$ (Wilcoxon matched-pairs signedranks test: $\mathrm{N}=31, \mathrm{~W}=-118, \mathrm{P}=0.2516)$.

\section{Upper and Lower Halves}

Coral coverage in each mooring area was compared between the upper and the lower halves of the faces. Coral coverage on the upper halves of the block faces was significantly higher than that on their lower halves in all three mooring areas (inshore area, Wilcoxon matched-pairs signed-ranks test: $\mathrm{N}=61, \mathrm{~W}=1587, \mathrm{P}<0.0001$; southern offshore area, Wilcoxon matched-pairs signed-ranks test: $\mathrm{N}=32, \mathrm{~W}=418, \mathrm{P}<0.0001$; northern offshore area, Wilcoxon matched-pairs signed-ranks test: $\mathrm{N}=34, \mathrm{~W}=515$, $\mathrm{P}<0.0001)$.

The ratios of lower half to upper half coverage was significantly different between the three areas (KruskalWallis test: $\mathrm{KW}=6.063, \mathrm{P}=0.0482$ ). Dunn's multiple comparisons post-test did not find which pair's medians of the ratio are significantly different. Because the medians for the two offshore areas were very close to each other, 0.360 and 0.365 , they were pooled together as one offshore area $(\mathrm{N}=66$, mean $\pm \mathrm{SE}=0.504 \pm 0.067)$, which was compared against the inshore area $(\mathrm{N}=61$, mean $\pm \mathrm{SE}=0.632 \pm 0.056)$. Mann-Whitney test of this comparison showed significant difference between the inshore and the offshore areas $(\mathrm{U}=1504, \mathrm{P}=0.0142)$. The relative difference in coverage of live coral between upper and lower halves of the block faces was significantly greater in the offshore area than in the inshore area.

\section{Light Intensity}

Light intensities in each mooring area were compared among north, east, south, and west orientations (Table 3). 
Table 4. Average current velocity, $\mathrm{cm} \times \mathrm{sec}^{-1}$.

\begin{tabular}{|c|c|c|c|c|}
\hline Mooring Area & Number of Measurements & Mean Velocity & Minimum Velocity & Maximum Velocity \\
\hline \hline Inshore & 98 & 4.85 & 0.2 & 24.5 \\
\hline Southern offshore & 54 & 5.17 & 0.8 & 25.5 \\
\hline Northern offshore & 44 & 5.12 & 0.3 & 17.7 \\
\hline
\end{tabular}

Kruskal-Wallis test showed that these intensities were significantly different in every area (inshore: $\mathrm{KW}=115.58$, $\mathrm{P}<0.0001$; southern offshore: $\mathrm{KW}=125.81, \mathrm{P}<0.0001$; northern offshore: $\mathrm{KW}=115.37, \mathrm{P}<0.0001)$.

Significant difference in light intensity was also found between mooring areas. Light intensity of the northern orientation in the inshore area was significantly lower than that in the southern orientation in the southern offshore area (Mann-Whitney test: $\mathrm{U}=5698, \mathrm{P}<0.0001$ ).

\section{Currents}

\section{Velocities}

Average current velocities were compared among the three mooring areas (Table 4). No significant differences were found (Kruskal-Wallis test: $\mathrm{KW}=2.063, \mathrm{P}=0.3565$ ).

\section{Prevailing Currents}

Directions of prevailing currents in each mooring area are generally parallel to the shoreline in that area (Fig. 5). Current velocities up the shoreline and down the shoreline were compared in each mooring area. The average velocity up the shoreline was significantly higher than that down the shoreline in the inshore (Wilcoxon signed rank test: $\mathrm{N}=98$, $\mathrm{W}=2220, \mathrm{P}<0.0001)$ and in the southern offshore (Wilcoxon signed rank test: $\mathrm{N}=54, \mathrm{~W}=822, \mathrm{P}=0.0004$ ) areas, but there was no significant difference between the directions in the northern offshore area (Wilcoxon signed rank test: $\mathrm{N}=44, \mathrm{~W}=199, \mathrm{P}=0.2480$ ).

\section{Zinc Corrosion (Integrated Water Motion)}

Repeated measures ANOVA failed to detect a significant difference in average zinc corrosion rates among the three mooring areas $(\mathrm{df}=34, \mathrm{~F}=1.891, \mathrm{P}=0.1448)$.

\section{DISCUSSION}

About two decades ago, Bonaire Marine Park installed concrete mooring blocks, $1 \mathrm{~m} \times 1 \mathrm{~m} \mathrm{x} 1 \mathrm{~m}$, along the shoreline of Kralendijk for yachts and boats to moor. Mixed coral colonies colonized the block faces. We find that distribution of the coral coverage is not random but instead follows patterns that this research sought to characterize and explain.

\section{Mooring Areas}

Coral coverage on the mooring blocks located close to shoreline near downtown Kralendijk (the inshore area) was about twice as much as on the adjacent blocks which are farther from the shoreline and closer to the natural reef (the southern offshore area). Because polluted rainwater enters sea water from the shore, the water near the shoreline is expected to be of a lower quality than water farther from it. Water quality is a known factor affecting coral development and poor water quality reduces coral establishment [13]. Thus higher coral coverage near the shore was unexpected and counter-intuitive. It suggests that a different factor, other than the water pollution from the shore, determined the observed pattern.

Studies have shown effects of proximity to a natural reef on coral settlement [14]. However, observed coral distribution on the mooring blocks in this study appears to be unrelated to the proximity of the natural reef. The coral coverage was significantly higher on the mooring blocks located in the northern offshore area than in the southern offshore area and was similar to the inshore area. The significant difference in coral coverage between the northern and the southern offshore areas, located equally close to the reef, suggests that the determining factor in this study was unrelated to possible biotic effects caused by reef inhabiting organisms found in other studies [15-19].

Exposure to light has been shown to affect multiple aspects of coral development [20-22]. However, factors determining coverage patterns on mooring blocks in this study appear to be unrelated to the illumination of mooring block faces. The inshore block faces which point north received only $65 \%$ of the amount of light reaching east-, south-, or west-oriented faces. If light intensity caused the differences in coral coverage, the northern faces would have significantly different amounts of coral from faces with other orientations. But no difference was found in coral coverage on faces with different orientations.

Inshore blocks received on average significantly more light than southern offshore ones and coral coverage on the inshore blocks was significantly higher than on the southern offshore ones. However, the northerly oriented faces of the inshore blocks received significantly less light than southerly oriented faces of the southern offshore blocks. In spite of this, northerly oriented faces of the inshore blocks had twice as much coral as southerly oriented faces of the southern offshore blocks. The lack of consistent relationship between coral coverage on the block faces and amounts of light reaching the faces indicates that light intensity did not determine observed coral distribution patterns in this study.

Directional water flow, i.e. current, is another factor known to affect multiple aspects of coral development [21, $23,24]$. However, the coverage patterns on mooring blocks in this study appear to be unrelated to the current velocity near the blocks. Average velocities of the currents in all three mooring areas were about $5 \mathrm{~cm} / \mathrm{sec}$, at least five times weaker than currents shown in the other studies to affect 

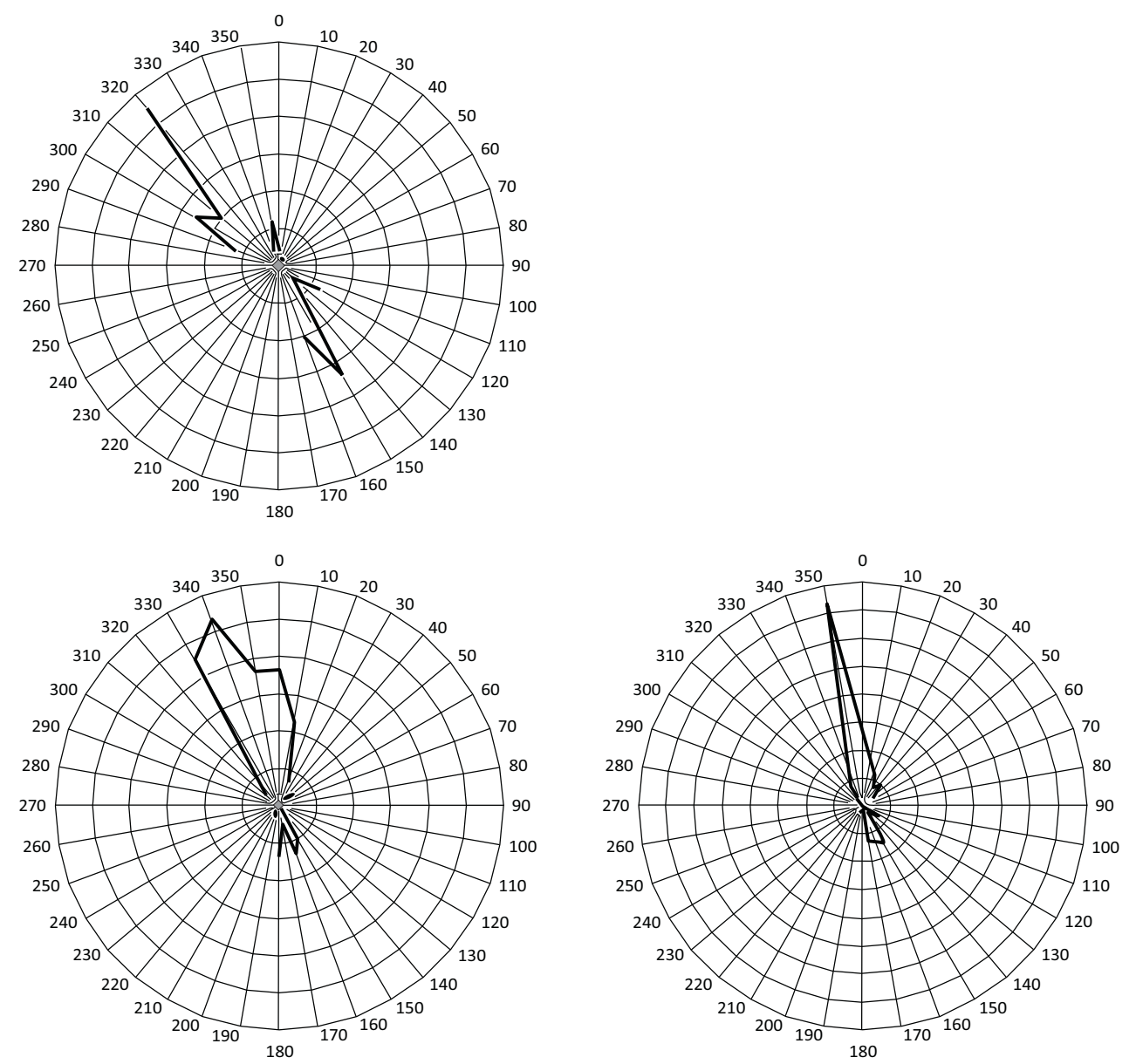

Fig. (5). Relative sum of current velocities for each current direction measured in the northern offshore (upper), southern offshore (lower left) and inshore (lower right) mooring areas.

coral recruitment, survival, or growth. Moreover, no differences in current velocities have been found among the three mooring areas.

Non-directional water motion caused by tides and waves also affects coral development [25, 26]. However, the measurements of galvanic corrosion failed to detect any difference in water motion among the mooring areas.

Additional factors that could lead to differences in coral coverage among the mooring areas are different amounts of sand surrounding mooring blocks, and different time durations the blocks were submerged. The sand might prevent coral recruitment by scouring the surface of the mooring blocks. However, the inshore moorings were located in the middle of the sand-flat, surrounded by sand, while the offshore moorings were located near the reef and surrounded by a mix of sand with hard coral rubble, small patches of live corals, sponges, and gorgonians. There was more sand around the inshore mooring blocks than around the offshore ones. If the amount of sand were preventing coral recruitment, then there would be less coral on the inshore moorings than on the offshore ones. The actual pattern was exactly opposite and thus, the sand around the moorings does not explain the coral coverage patterns.

Chronologically, all the mooring blocks in this study were installed over one year and half between 1994 and 1996. The offshore moorings were installed first, from south to north, and then the inshore moorings were installed. This timing of mooring installation does not correspond to the patterns of coral coverage present.

Another environmental factor known to detrimentally affect multiple aspects of coral development is sediment disturbance [3, 27-31]. If this was the factor determining coral coverage patterns on the mooring blocks, the disturbance affected mostly the southern offshore mooring area and to a lesser extent the inshore and the northern offshore areas. Examining the vicinity of the mooring areas suggests a possible source of such disturbance: the plume of muddy "marine snow" from the port (Fig. 2).

The offshore moorings are located near the reef drop-off, and thus, on the axis of the plume movement. The southern offshore mooring blocks are the closest to the plume's source, the port, and thus they would be most affected. As the plume moves farther away from its source it settles and disperses, and its effect on the blocks weakens. In addition, the lack of a prevailing current direction in the northern mooring area diminishes the plume effect in that area. The inshore mooring blocks would be less affected than the southern offshore ones because the inshore blocks are located away from the plume movement axis. Thus, the plume of sediments mechanically disturbed in the port and drifted by the prevailing currents can consistently explain the observed patterns of coral distribution among the three mooring areas. 


\section{Right and Left Halves of Block Faces}

The faces of the inshore mooring blocks which were oriented against the prevailing current had significantly more coral coverage on their right halves than on their left halves. No asymmetry in the coral coverage between the right and left halves has been found in other mooring areas or on faces oriented away from the current. The plume of disturbed sediment described in the previous section can consistently explain this pattern. The suspended sediments' concentration varies horizontally and vertically, as viewed in the direction of the plume movement (Fig. 3). The axis of the plume is near the offshore mooring area - this is where the concentration of the suspended sediment is the highest. This concentration decreases upward and sidewise. The concentration of suspended sediment differs between right and left halves of the inshore block faces oriented toward the upcoming plume: the right halves being farther from the plume axis receive less sediment than the left halves (Fig. 3). Although this difference is not as pronounced as the difference between the inshore and the offshore block faces, it could be sufficient for coral larvae to settle preferentially on the right rather than the left halves as they explore quality of attachment sites by probing, crawling, bouncing and swimming across them [14, 32-34].

There is no or little difference in sediment concentrations between the right and the left halves of the offshore block faces because they are located at or near the plume axis; the horizontal gradient of sediment concentration is greater closer to the shore than near the plume axis (Fig. 3). This explains why corals on the offshore block faces did not exhibit right $v s$. left differences.

Sediment concentrations in the plume do not differ between the right and the left halves of the faces oriented away from the upcoming plume because of the hydrodynamics of the water flow around the blocks [35]. That is why the corals exhibited right settlement preference only on the faces oriented against the current, i.e. facing into the upcoming plume.

\section{Upper and Lower Halves of Block Faces}

There was a significant difference in coral coverage between the upper and the lower halves of the block faces. The vast majority, 109 out of 127, mooring block faces had more corals on their upper than on their lower halves. This ratio held for the inshore, 51 out of 61 , and for the offshore, 58 out of 66 mooring block faces.

Several environmental factors could be considered to explain this asymmetry. One such factor is the effect of waves. The faces' upper parts are closer to the surface and thus are more affected by waves than their lower parts. The enhanced water motion could be a cause of enhanced coral growth on the upper parts. But if it were so, then a stronger effect would be expected inshore than offshore because the inshore moorings are shallower than the offshore ones. The top of the inshore mooring blocks is about $2 \mathrm{~m}$ deep, and their base is about $3 \mathrm{~m}$ deep - a $50 \%$ difference, while the top of the offshore mooring blocks is at about $4 \mathrm{~m}$ deep and the base at about $5 \mathrm{~m}$ deep - only a $25 \%$ difference. Thus, the difference between upper and lower half coral coverage would be greater on the inshore than on the offshore moorings. However, as found here, the difference between upper and lower half coral coverage was significantly greater on the offshore than on the inshore moorings.

The asymmetry between the upper and lower half coverage could be caused by different light intensities. The faces' upper parts receive more light than their lower parts. Because the inshore moorings are shallower than the offshore ones, just as in the case of the wave effect described earlier, the light effect is stronger on the inshore moorings than on the offshore ones. Again, the difference between upper and lower half coral coverage would be greater on the inshore than on the offshore moorings, while the opposite pattern is found here.

Another possible explanation of the vertical asymmetry could be that sand from the bottom scours the faces' lower parts more than their upper parts. Because the inshore moorings are surrounded by larger amounts of sand than the offshore ones, the sand effect is stronger on the inshore moorings than offshore. Thus, the difference between upper and lower half coral coverage would be greater on the inshore than on the offshore moorings - opposite to the actual pattern found here.

If the asymmetry between the upper and lower half coverage were caused by any of the factors above or their combination, the asymmetry would be more pronounced in the inshore rather than the offshore areas. Contrary to this prediction, the difference between upper and lower half coral coverage was significantly greater on the offshore than on the inshore moorings. On the inshore mooring block faces, about twice as much coral covered the upper halves compared to the lower halves, but on the offshore moorings three times as much.

The observed vertical asymmetry pattern is inconsistent with possible effects of waves, light, and sand, but it is consistent with the effects of the plume of suspended sediments described earlier. The concentration of sediments is highest at the plume's axis and drops upward and sidewise (Fig. 3). On both the offshore and the inshore blocks, concentration of sediments is higher near the base than near the top. The vertical gradient in sediment concentration is greater near the plume axis than closer to the shore, i.e. greater on the offshore blocks than on the inshore ones (Fig. 3). Accordingly, the difference in coral amounts between the upper and the lower halves of the block faces is greater on the offshore blocks than on the inshore ones.

\section{CONCLUSION}

The patterns of coral coverage distribution between the three mooring areas, as well as the horizontal and vertical patterns of coral coverage on the mooring block faces correspond to detrimental effects on coral by this plume of suspended sediment drifting along the reef from the port. They do not correspond to other factors generally known to affect coral development. This consistent correspondence strongly, albeit indirectly supports the proposed explanation of the distribution patterns. Repeated measurements of concentration of sediments suspended in water and accumulated on the mooring faces would provide more direct support for this explanation. 
This study suggests a strong detrimental effect on coral development by sediment disturbance upstream of the coral site. This effect needs to be considered in coral restoration projects, and the relative position between coral sites and areas of disturbance has to be chosen accordingly.

\section{CONFLICT OF INTEREST}

The authors confirm that this article content has no conflict of interest.

\section{ACKNOWLEDGEMENTS}

CIEE Research Station Bonaire provided lab facilities and equipment, and Dive Friends Bonaire N. V. provided compressed air tanks used for conducting this study.

\section{REFERENCES}

[1] RPM Bak, Nieuwland G, Meesters EH. Coral growth rates revisited after 31 years: what is causing lower extension rates in Acropora palmata? Bul Mar Sci 2009; 84: 287-94

[2] Meesters EH, Hilterman M, Kardinaal E, Keetman M, de Vries M, Bak RPM. Colony size-frequency distributions of scleractinian coral populations: spatial and interspecific variation. Mar Ecol Prog Ser 2001; 209: 43-54.

[3] Dikou A, Van WR. Partial colony mortality reflects coral community dynamics: a fringing reef study near a small river in Okinawa, Japan. Mar Pollut Bull 2006 ; 52: 269-80.

[4] Brown BE, Dunne RP. Environmental controls of patch-reef growth and development. Mar Biol 1980 ; 56: 85-96.

[5] Genin A, Dayton PK, Lonsdale PF, Spiess FN. Corals on seamount peaks provide evidence of current acceleration over deep-sea topography. Nature $1986 ; 322: 59-61$.

[6] Bak RPM, Meesters EH. Coral population structure: the hidden information of colony size-frequency distributions. Mar Ecol Prog Ser 1998; 162: 301-6.

[7] Vermeij MJA. Early life-history dynamics of Caribbean coral species on artificial substratum: the importance of competition, growth and variation in life-history strategy. Coral Reefs 2006; 25: 59-71.

[8] Spieler RE, Gilliam DS, Sherman RL. Artificial substrate and coral reef restoration: what do we need to know to know what we need. Bull Mar Sci 2001; 69: 1013-30.

[9] Schumacher H. Development of coral communities on artificial reef types over 20 years (Eilat, Red Sea). Proceedings of the 6th International Coral Reef Symposium, Australia 1988; 3: 379-84.

[10] Baynes TW, Szmant AM. Effect of current on the sessile benthic community structure of an artificial reef. Bull Mar Sci 1989; 44: $545-66$.

[11] McGehee MA. Comparisons of water motion in coral reefs by measuring corrosion rates of dissimilar metals. Caribb J Sci 1988; 34: 286-97.

[12] Boizard SD, DeWreede RE. Inexpensive water motion measurement devices and techniques and their utility in macroalgal ecology: a review. Sci Asia 2006; 32: 43-9.

[13] Ritson-Williams R, Arnold SN, Fogarty ND, Steneck RS, Vermeij MJA, Paul VJ. New perspectives on ecological mechanisms affecting coral recruitment on reefs. Smithson Contrib Mar Sci 2009; 38: 437-57.

[14] Gleason DF, Danilowicz BS, Nolan CJ. Reef waters stimulate substratum exploration in planulae from brooding Caribbean corals. Coral Reefs 2009; 28:549-54.
[15] Christiansen NA, Ward S, Harii S, Tibbetts IR. Grazing by a small fish affects the early stages of a post-settlement stony coral. Coral Reefs 2009; 28: 47-51.

[16] Mumby PJ. Herbivory versus corallivory: Are parrotfish good or bad for Caribbean coral reefs? Coral Reefs 2009; 28: 683-90.

[17] Cole AJ, Lawton RJ, Pratchett MS, Wilson SK. Chronic coral consumption by butterflyfishes. Coral Reefs 2011 ; 30: 85-93.

[18] Filkovsky G, Hoback WW. Effects of positional overlap on interactions and co-occurrence of follower fishes in benthic foraging associations. Open Mar Biol J 2011; 5: 68-72.

[19] Marhaver KL, Vermeij MJA, Rohwer F, Sandin SA. JanzenConnell effects in a broadcast-spawning Caribbean coral: Distance dependent survival of larvae and settlers. Ecology 2013; 94: 14660 .

[20] Kaniewska P, Magnusson SH, Anthony KRN, Reef R, Kühl M, and Hoegh-Guldberg O. Importance of macro- versus microstructure in modulating light levels inside coral colonies. J Phycol 2011; 47: 846-60.

[21] Osinga R, Schutter M, Griffioen B, Wijffels RH, Verreth JAJ, Shafir S, Henard S, Taruffi M, Gili C, Lavorano S. The biology and economics of coral growth. Mar Biotechnol 2011; 13: 658-71.

[22] Bernal-Sotelo F, Acosta A. The relationship between physical and biological habitat conditions and hermatypic coral recruits abundance within insular reefs (Colombian Caribbean). Int J Tropical Biol 2012; 60: 995-1014.

[23] Nakamura T. Importance of water-flow on the physiological responses of reef-building corals. Galaxea, J Coral Reef Studies 2010; 12: 1-14.

[24] Schutter M, Crocker J, Paijmans A, et al. The effect of different flow regimes on the growth and metabolic rates of the scleractinian coral Galaxea fascicularis. Coral Reefs 2010 ; 29: 737-48.

[25] Reidenbach MA, Koseff JR, Koehl MAR. Hydrodynamic forces on larvae affect their settlement on coral reefs in turbulent, wavedriven flow. Limnol Oceanogr 2009; 54: 318-30.

[26] Chollett I, Mumby PJ. Predicting the distribution of Montastraea reefs using wave exposure. Coral Reefs 2012; 31: 493-503.

[27] Fabricius KE, Wolanski E. Rapid smothering of coral reef organisms by muddy marine snow. Est Coast Shelf Sci 2000; 50 : 115-20.

[28] Golbuu Y, van Woesik R, Richmond RH, Harrison P, Fabricius KE. 2011. River discharge reduces reef coral diversity in Palau. Mar Pollut Bull 2011; 62: 824-31.

[29] Erftemeijer PLA, Riegl B, Hoeksema BW, Todd PA. Environmental impacts of dredging and other sediment disturbances on corals: A review. Mar Pollut Bull 2012; 64: 173765 .

[30] Flores FM, Hoogenboom O, Smith LD, Cooper TF, Abrego D, Negri AP. Chronic exposure of corals to fine sediments: Lethal and sub-lethal impacts. PLoS ONE 2012; 7: e37795.

[31] Weber M, de Beer D, Lott C, Polerecky L, Kohls K, Abed RMM, et al. Mechanisms of damage to corals exposed to sedimentation. PNAS 2012; 109: E1558-E1567.

[32] Vermeij MJA, Bak RPM. Corals on the move: Rambling of Madracis pharensis polyps early after settlement. Coral Reef 2002; 21: 262-3.

[33] Harii S, Nadaoka K, Yamamoto M, Iwao K. Temporal changes in settlement, lipid content and lipid composition of larvae of the spawning hermatypic coral Acropora tenuis. Mar Ecol Prog Ser 2007; 346: 89-96.

[34] Pizarro V, Thomason JC. How do swimming ability and behaviour affect the dispersal of coral larvae. Proceedings of the $11^{\text {th }}$ International Coral Reef Symposium, Ft. Lauderdale, Florida, 7-11 July 2008; Session number 14: 454-8.

[35] Krajnovič S, Davidson L. Flow around a three-dimensional bluff body. $9^{\text {th }}$ International Symposium on Flow Visualization, HeriotWatt University, Edinburgh (Editors Carlomagno GM, Grant I) 2000; 177: 1-10. 